\title{
Using the lymph nodal ratio to predict the risk of locoregional recurrence in lymph node-positive breast cancer patients treated with mastectomy without radiation therapy
}

San-Gang Wu ${ }^{1 \dagger}$, Yong Chen ${ }^{2,3+}$, Jia-Yuan Sun ${ }^{2,3+}$, Feng-Yan Li ${ }^{2,3}$, Qin Lin ${ }^{1}$, Huan-Xin Lin ${ }^{2,3}$ and Zhen-Yu He $e^{2,3 *}$

\begin{abstract}
Background: To evaluate the prognostic value of axillary lymph node ratio (LNR) as compared to the number of involved nodes ( $\mathrm{pN}$ stage) in patients with axillary lymph node-positive breast cancer treated with mastectomy without radiation.

Methods: We performed a retrospective analysis of the clinical data of patients with stage II-III node-positive breast cancer (N=1068) between 1998 and 2007. Locoregional recurrence-free survival (LRFS) and overall survival (OS) were compared based on the LNR and pN staging.

Results: A total of 780 cases were classified as pN1, 183 as pN2, and 105 as pN3. With respect to LNR, 690 cases had a LNR from 0.01-0.20, 269 cases a LNR from 0.21-0.65, and 109 cases a LNR > 0.65. The median follow-up time was 62 months. Univariate analysis showed that both LNR and pN stage were prognostic factors of LRFS and OS $(p<0.05)$. Multivariate analysis indicated that LNR was an independent prognostic factor of LRFS and OS $(p<0.05)$. pN stage had no significant effect on LRFS or OS ( $p>0.05$ ). In subgroup analysis, the LNR identified groups of patients with different survival rates based on $\mathrm{pN}$ stage.
\end{abstract}

Conclusions: LNR is superior to $\mathrm{pN}$ staging as a prognostic factor in lymph node-positive breast cancer after mastectomy, and should be used as one of the indications for adjuvant radiation therapy.

Keywords: Breast cancer, Lymph node ratio, Mastectomy, Recurrences, Radiotherapy

\section{Introduction}

Studies have shown that radiation therapy improves locoregional control of axillary lymph node-positive breast cancer, and thereby benefits survival [1-3]. The positive lymph node status has been used as an indicator for adjuvant radiotherapy after mastectomy [4,5]. However, overall outcomes can be variable depending on the extent of axillary lymph node removal. Additionally, the decision to perform radiation therapy is in part physician dependent.

\footnotetext{
* Correspondence: hezhy@sysucc.org.cn

${ }^{\dagger}$ Equal contributors

${ }^{2}$ State Key Laboratory of Oncology in Southern China, Sun Yat-Sen University Cancer Center, Guangzhou 510060, People's Republic of China

${ }^{3}$ Department of Radiation Oncology, Sun Yat-Sen University Cancer Center, Guangzhou 510060, People's Republic of China

Full list of author information is available at the end of the article
}

The lymph node ratio (LNR) is defined as the ratio of the number of positive axillary lymph nodes to the number of removed axillary lymph nodes, and has attracted a great deal of attention. Veronesi et al. [6] has suggested that use of the LNR may minimize the difference between clinical judgment and the real status of the lymph nodes that arises due to differing physician practices. Currently, studies on the LNR have been mainly focused on patients with 1-3 positive nodes $[7,8]$. The reliability of the LNR in predicting the prognosis in patients with greater than 3 positive nodes has rarely been addressed. In this retrospectively study, we compared the prognostic values of the LNR and number of involved nodes $(\mathrm{pN})$ staging in 1068 patients with axillary lymph node-positive breast cancer without radiation therapy after mastectomy to 
Table 1 Patients characteristics and univariate analysis of prognostic factors for survival

\begin{tabular}{|c|c|c|c|c|c|c|c|}
\hline \multirow[t]{2}{*}{ Characteristic } & \multirow[b]{2}{*}{$\mathrm{n}$} & \multicolumn{3}{|l|}{ LRFS } & \multicolumn{3}{|l|}{ OS } \\
\hline & & 5-year (\%) & 10-year (\%) & $\mathrm{p}$ & 5-year (\%) & 10-year (\%) & $\mathrm{p}$ \\
\hline \multicolumn{8}{|l|}{ Age $(y)$} \\
\hline$\leq 35$ & 134 & 76.0 & 70.4 & $0.020^{*}$ & 74.4 & 66.4 & 0.113 \\
\hline$>35$ & 934 & 85.4 & 82.7 & & 80.5 & 67.4 & \\
\hline \multicolumn{8}{|l|}{ Menopausal status } \\
\hline Premenopausal & 697 & 81.8 & 79.3 & $0.026^{*}$ & 80.3 & 68.9 & 0.589 \\
\hline Postmenopausal & 371 & 89.0 & 85.1 & & 78.7 & 63.4 & \\
\hline \multicolumn{8}{|l|}{ Tumor size } \\
\hline $\mathrm{T} 1-2$ & 916 & 86.4 & 83.6 & $<0.001^{*}$ & 81.8 & 70.9 & $<0.001^{*}$ \\
\hline T3-4 & 97 & 70.2 & 70.2 & & 61.2 & 36.1 & \\
\hline Unknown & 55 & & & & & & \\
\hline \multicolumn{8}{|l|}{ No of positive lymph nodes } \\
\hline pN1 (1-3) & 780 & 88.7 & 86.1 & $<0.001^{*}$ & 86.1 & 77.7 & $<0.001^{*}$ \\
\hline pN2 (4-9) & 183 & 77.0 & 73.0 & & 69.7 & 51.0 & \\
\hline pN3 $(\geq 10)$ & 105 & 60.6 & 53.8 & & 49.9 & 20.8 & \\
\hline \multicolumn{8}{|l|}{ Lymph node ratio } \\
\hline$<0.20$ & 690 & 90.2 & 87.7 & $<0.001^{*}$ & 87.1 & 78.6 & $<0.001^{*}$ \\
\hline $0.21-0.65$ & 269 & 78.6 & 74.9 & & 75.1 & 60.9 & \\
\hline$>0.65$ & 109 & 57.5 & 52.3 & & 44.3 & 21.5 & \\
\hline \multicolumn{8}{|l|}{ ER status } \\
\hline Positive & 599 & 85.9 & 84.4 & $0.008^{*}$ & 83.9 & 69.0 & $<0.001^{*}$ \\
\hline Negative & 393 & 81.0 & 76.7 & & 72.2 & 64.2 & \\
\hline Unknown & 76 & & & & & & \\
\hline \multicolumn{8}{|l|}{ PR status } \\
\hline Positive & 652 & 85.9 & 83.4 & $0.008^{*}$ & 83.0 & 72.6 & $<0.001^{*}$ \\
\hline Negative & 340 & 80.3 & 77.6 & & 72.3 & 57.0 & \\
\hline Unknown & 76 & & & & & & \\
\hline \multicolumn{8}{|l|}{ HER-2-neu status } \\
\hline Positive & 321 & 81.8 & 79.7 & 0.077 & 75.6 & 66.2 & $0.026^{*}$ \\
\hline Negative & 585 & 85.5 & 82.0 & & 82.7 & 71.2 & \\
\hline Unknown & 162 & & & & & & \\
\hline \multicolumn{8}{|l|}{ Chemotherapy regimen } \\
\hline CMF & 142 & 82.1 & 79.6 & 0.332 & 76.0 & 60.1 & 0.069 \\
\hline Anthracycline and/or taxane & 850 & 84.9 & 81.9 & & 81.5 & 71.0 & \\
\hline None/unknown & 76 & & & & & & \\
\hline \multicolumn{8}{|l|}{ Hormone therapy } \\
\hline Yes & 718 & 85.7 & 82.5 & $0.032^{*}$ & 83.7 & 70.5 & $<0.001^{*}$ \\
\hline None & 350 & 81.4 & 78.8 & & 71.2 & 60.4 & \\
\hline
\end{tabular}

LRFS, Locoregional recurrence-free survival; $O S$, Overall survival; $E R$, Estrogen receptor; $P R$, Progesterone receptor; Her-2, Human epithelial growth factor receptor family 2; CMF, Cyclophosphamide, methotrexate, and 5-fluorouracil.

${ }^{*} \mathrm{p}<0.05$ indicates a significant difference. 
determine the value of the LNR as an indicator for adjuvant radiation therapy in these patients.

\section{Materials and methods}

\section{Study population}

The study was performed in accordance with the Declaration of Helsinki and was approved by the ethics committee of Sun Yat-Sen University Cancer Center. Written consent was given by the patients for their information to be stored in the hospital database and used for research. A total of 1068 female stage II-III breast cancer patients treated between January 1998 and May 2007 at the Sun Yat-sen University Cancer Center were included in this study. All patients were diagnosed with unilateral breast cancer without initial distant metastasis, and underwent mastectomy and axillary lymph node dissection. Staging was based on the 2009 7th edition of the American Joint Committee on Cancer (AJCC) staging system, and patients with a post-mastectomy pathological stage of T14N1-3M0 were included. In all cases, the tumor was completely dissected and surgical margins were negative.
No neo-adjuvant therapy was administered before surgery, and no adjuvant radiotherapy was provided after surgery. No patients had any serious comorbid conditions.

\section{Clinical and pathological factors and lymph node status}

Clinical and pathological characteristics were used to assess the risk of locoregional recurrence and death, and included age, menopausal status, $\mathrm{T}$ stage, $\mathrm{pN}$ stage, and estrogen receptor (ER), progesterone receptor (PR), and human epithelial growth factor receptor family 2 (Her-2) status. $\mathrm{T}$ staging and $\mathrm{pN}$ staging were determined according to the AJCC staging system (7th edition, 2009). LNR classifications were based on the report by Vinh-Hung et al. [9]. Patients were classified into 3 groups: LNR 0.01-0.20, LNR $0.21-0.65$, and LNR $>0.65$.

\section{Follow-up and survival endpoints}

Follow-up was scheduled every 3-6 months after surgery. Locoregional recurrence-free survival (LRFS) and overall survival (OS) were the primary study endpoints.
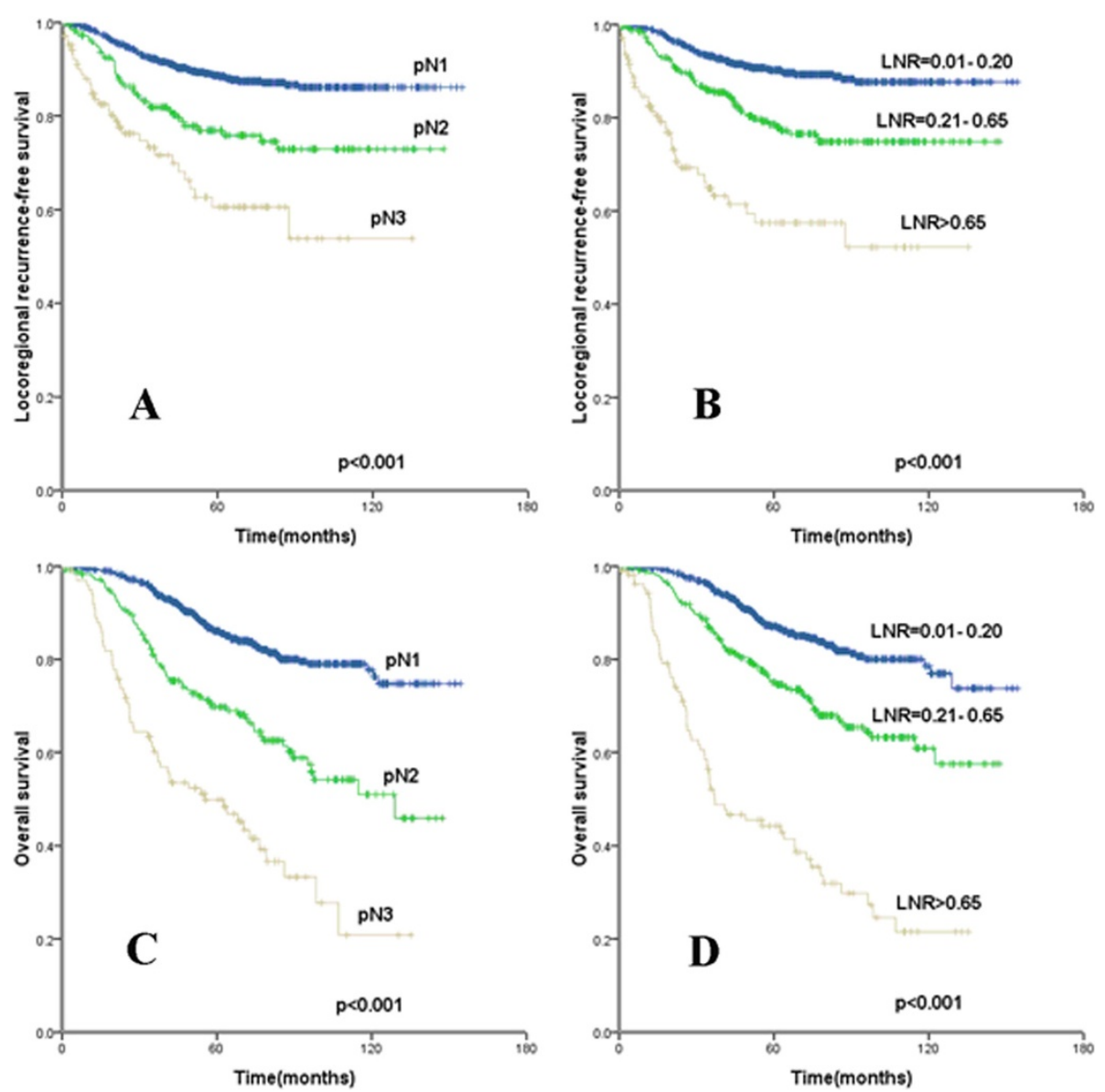

Figure 1 Kaplan-Meier cumulative survival curves for different lymph node ratio (LNR) and pN stage. (A, B) Locoregional recurrence-free survival and $(\mathbf{C}, \mathbf{D})$ overall survival for $(\mathbf{A}, \mathbf{C}) \mathrm{pN}$ and $(\mathbf{B}, \mathbf{D}) L N R$. 
Locoregional recurrence was defined as pathologically confirmed relapse on the chest wall, supra- and infraclavicular fossa, axillary area, or internal mammary region. Mortality was defined as breast cancer-related death.

\section{Statistical analysis}

Data were analyzed using SPSS 16.0 software. KaplanMeier curves were generated to compare the survival rates. The statistical significance of data was analyzed by log-rank test. Cox stepwise regression analysis was used for multivariate analysis, and significant variables in univariate analysis as indicated by $\mathrm{p}<0.05$ were included in the Cox model. Statistical significance was set at $\mathrm{p}<0.05$.

\section{Results}

Clinical and pathological factors and treatment protocol A total of 1068 patients with a median age of 47 years (range, 23-90 years) were included in the study. The clinical and pathological characteristics of the patients are summarized in Table 1. The median numbers of axillary lymph nodes removed and positive lymph nodes were 15 (1-45) and $2(1-44)$, respectively. Based on the $\mathrm{pN}$ staging system, 780 cases $(73.1 \%)$ were classified as $\mathrm{N} 1,183$ cases $(17.1 \%)$ as $\mathrm{N} 2$, and 105 cases $(9.8 \%)$ as N3. The median LNR was $0.14(0.03-1.00)$. There were 690 cases $(64.6 \%)$ with a LNR from 0.01-0.20, 269 (25.2\%) with a LNR from 0.21-0.65, and 109 (10.2\%) with a LNR $>0.65$. A total of 1032 patients (96.6\%) received chemotherapy following surgery. Among them, 142 cases underwent a regimen consisting of cyclophosphamide, methotrexate, and 5-fluorouracil (CMF), and 890 cases received regimens with anthracycline and/or taxane. The other 36 patients did not receive any chemotherapy. All patients with a positive hormone receptor status were treated with endocrine therapy using tamoxifen and aromatase inhibitors after chemotherapy. Herceptin was used for 4 patients with Her-2 overexpression.

\section{Survival and disease progression}

The median follow-up time for all patients was 62 months (5-154 months). Locoregional recurrence occurred in 155

Table 2 Multivariate analysis of survival by lymph node ratio and pN stage

\begin{tabular}{|c|c|c|c|c|}
\hline \multirow[t]{2}{*}{ Characteristic } & \multicolumn{2}{|l|}{ LRFS } & \multicolumn{2}{|l|}{ OS } \\
\hline & HR (95\% Cl) & $\mathrm{p}$ & HR $(95 \% \mathrm{Cl})$ & $\mathrm{p}$ \\
\hline \multicolumn{5}{|l|}{ Age (y) } \\
\hline$\leq 35$ vs. $>35$ & $1.664(1.082-2.558)$ & $0.020^{*}$ & - & \\
\hline \multicolumn{5}{|l|}{ Menopausal status } \\
\hline Pre- vs. postmenopausal & $1.623(1.106-2.383)$ & 0.105 & - & \\
\hline \multicolumn{5}{|l|}{ Tumor size } \\
\hline T3-4 vs. T1-2 & $1.636(1.029-2.600)$ & 0.037 & $1.392(0.917-2.113)$ & 0.121 \\
\hline \multicolumn{5}{|l|}{ ER status } \\
\hline Negative vs. positive & $1.536(1.095-2.155)$ & $0.013^{*}$ & $1.054(0.699-1.590)$ & 0.802 \\
\hline \multicolumn{5}{|l|}{ PR status } \\
\hline Negative vs. positive & $1.626(1.148-2.302)$ & 0.317 & $1.490(1.040-2.136)$ & $0.030^{*}$ \\
\hline \multicolumn{5}{|l|}{ HER-2-neu status } \\
\hline Positive vs. negative & - & & $1.208(0.888-1.644)$ & 0.228 \\
\hline \multicolumn{5}{|l|}{ Hormone therapy } \\
\hline None vs. yes & $1.180(0.731-1.904)$ & 0.498 & $1.570(1.093-2.255)$ & $0.015^{*}$ \\
\hline \multicolumn{5}{|l|}{ Lymph node ratio } \\
\hline$<0.20$ & 1 (Reference) & & 1 (Reference) & \\
\hline $0.21-0.65$ & $1.886(1.273-2.794)$ & $0.002^{*}$ & $1.964(1.387-2.782)$ & $<0.001^{*}$ \\
\hline$>0.65$ & $5.013(3.191-7.877)$ & $<0.001^{*}$ & $7.381(5.161-10.557)$ & $<0.001^{*}$ \\
\hline \multicolumn{5}{|c|}{ Number of positive lymph nodes } \\
\hline pN1 & 1 (Reference) & & & \\
\hline pN2 & $0.828(0.476-1.442)$ & 0.522 & $1.327(0.808-2.179)$ & 0.263 \\
\hline pN3 & $0.894(0.437-1.828)$ & 0.907 & $1.654(0.904-3.027)$ & 0.103 \\
\hline
\end{tabular}

LRFS, Locoregional recurrence-free survival; OS, Overall survival; ER, Estrogen receptor; PR, Progesterone receptor; Her-2, Human epithelial growth factor receptor family 2; $H R$, Hazard ratio; $\mathrm{Cl}$, Confidence interval.

${ }^{*} \mathrm{p}<0.05$ indicates a significant difference. 
cases. The 5- and 10-year LRFS rates were $84.3 \%$ and $81.3 \%$, respectively. The median time to recurrence was 23 months (range, 4-91 months). Supraclavicular fossa recurrence occurred in 73 cases $(47.1 \%)$, chest wall recurrence in 47 cases (30.3\%), axillary lymph node recurrence in 3 cases $(1.9 \%)$, internal mammary recurrence in 2 cases (1.3\%), and infraclavicular fossa recurrence in 2 cases (1.3\%). There were 28 cases in which recurrence occurred at $\geq 2$ sites $(18.1 \%)$. A total of 240 patients died, among whom 229 died as a result of breast cancer and 11 died of other disorders. The 5- and 10-year OS rates were $79.7 \%$ and $67.3 \%$, respectively.

\section{Analysis of prognostic factors}

Univariate analysis showed that age, menopausal status, $\mathrm{T}$ stage, $\mathrm{pN}$ stage, LNR, ER and PR status, and hormone therapy were all prognostic factors of LRFS $(\mathrm{p}<0.05)$. The 10-year LRFS rates were $86.1 \%, 73.0 \%$, and $53.8 \%$ for stage $\mathrm{pN} 1, \mathrm{pN} 2$, and $\mathrm{pN} 3$, respectively $(\mathrm{p}<0.001)$, while the rates were $87.7 \%, 74.9 \%$, and $52.3 \%$ for a LNR of $0.01-0.20$, LNR of $0.21-0.65$, and a LNR > 0.65, respectively $(\mathrm{p}<0.001)$. $\mathrm{T}$ stage, $\mathrm{pN}$ stage, LNR, ER, PR, and Her-2 status, and hormone therapy were all prognostic factors of OS $(p<0.05)$ (Table 1 and Figure 1).

The variables demonstrating statistical significance by univariate analysis were further analyzed using multivariate analysis in the Cox regression model. When $\mathrm{pN}$ and LNR were included as covariants, the LNR remained an independent prognostic factor for LRFS and OS $(\mathrm{p}<0.05)$, with a higher LNR indicating a higher risk, but $\mathrm{pN}$ stage exhibited no effect on LRFS and OS (p>0.0 5) (Table 2).

\section{Prognostic significance of LNR based on pN stage}

The subgroup analysis of the prognostic significance of LNR according to different $\mathrm{pN}$ stages is shown in Table 3 and Figure 2. For pN1 patients, the 5-year and 10-year LRFS for a LNR of $0.21-0.65$ were $80.4 \%$ and $74.8 \%$, respectively, which were significantly lower than values of 90.3\% and $88.2 \%$, respectively, when the LNR was $<0.20$ (p 0.002). The 5-year LRFS for $\mathrm{pN} 2$ patients with a LNR of $0.01-0.20,0.21-0.65$, and $>0.65$, were $80.0 \%, 82.1 \%$, and $44.6 \%$, respectively $(\mathrm{p}<0.001)$. Among $\mathrm{pN} 3$ patients, the LNR had no impact the prognosis, but the LRFS was lower, the 5-year LRFS was 66.7\%, 59.2\%, and 66.2\% for patients with a LNR of 0.01-0.20, $0.21-0.65$, and > 0.65, respectively $(p=0.508)$. The LNR was a prognosis factor with respect to $\mathrm{OS}$ based on $\mathrm{pN}$ stage.

\section{Discussion}

Although significant progress has been made in understanding molecular biomarkers of breast cancer, axillary lymph node status remains one of the fundamental
Table 3 Impact of lymph node ratio according to different $\mathbf{p N}$ stages

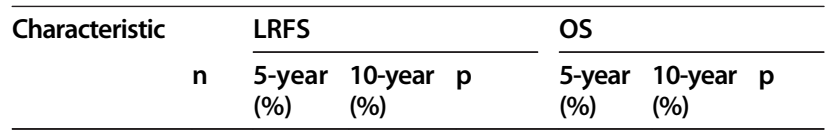

pN1 (1-3

positive nodes)

Lymph node

ratio

\begin{tabular}{llllllll}
$<0.20$ & 667 & 90.3 & 88.2 & $0.002^{*}$ & 87.3 & 79.0 & 0.054 \\
$0.21-0.65$ & 107 & 80.0 & 74.8 & & 80.1 & 71.0 & \\
$>0.65$ & 6 & 83.3 & - & & 75.0 & - & \\
pN2 (4-9 & & & & & & & \\
positive nodes) & & & & & & & \\
Lymph & & & & & & & \\
node ratio & & & & & & & \\
$<0.20$ & 16 & 80.0 & - & $<0.001^{*}$ & 84.4 & 56.3 & $0.004^{*}$ \\
$\quad 0.21-0.65$ & 141 & 82.1 & 77.2 & & 72.0 & 55.2 & \\
$>0.65$ & 26 & 44.6 & - & & 49.2 & 26.2 & \\
pN3 ( $\geq 10$ & & & & & & & \\
positive nodes) & & & & & & & \\
Lymph & & & & & & & \\
node ratio & & & & & & & \\
$<0.20$ & 7 & 66.7 & - & 0.508 & 80.0 & - & $0.013^{*}$ \\
$0.21-0.65$ & 21 & 59.2 & - & & 69.3 & - & \\
$>0.65$ & 77 & 62.2 & 49.8 & & 41.4 & 15.4 & \\
\hline
\end{tabular}

LRFS, Locoregional recurrence-free survival; OS, Overall survival.

$\mathrm{p}<0.05$ indicates a significant difference.

prognostic factors that guides the decision for postmastectomy radiation therapy $[4,5]$. Presently, the tumor, regional lymph node, metastasis (TNM) staging system, established by the AJCC, is accepted and utilized worldwide. In this system, the $\mathrm{pN}$ staging of axillary lymph nodes is based on the absolute number of lymph nodes. Although easy to use, the accuracy of the approach may be affected by the number of removed axillary lymph nodes, and thus may be subject to unintended variability. In the present study, we explored the prognostic value of LNR in stage II-III nodepositive breast cancer patients without radiotherapy after mastectomy, and demonstrated that the LNR can better predict tumor recurrence and mortality.

The $82 \mathrm{~b}$ and $82 \mathrm{c}$ randomized trials of radiotherapy conducted by the Danish Breast Cancer Cooperative Group provided evidence that postoperative adjuvant radiotherapy has therapeutic value in axillary lymph node-positive breast cancer; however, the median number lymph nodes removed was 7, suggesting that adjuvant therapy used at that time appears insufficient [10]. Nagao et al. [11] showed that the LRFS rate was $8.7 \%$ with radiotherapy and $7.3 \%$ without radiotherapy after mastectomy in lymph node-positive nodes patients, with 

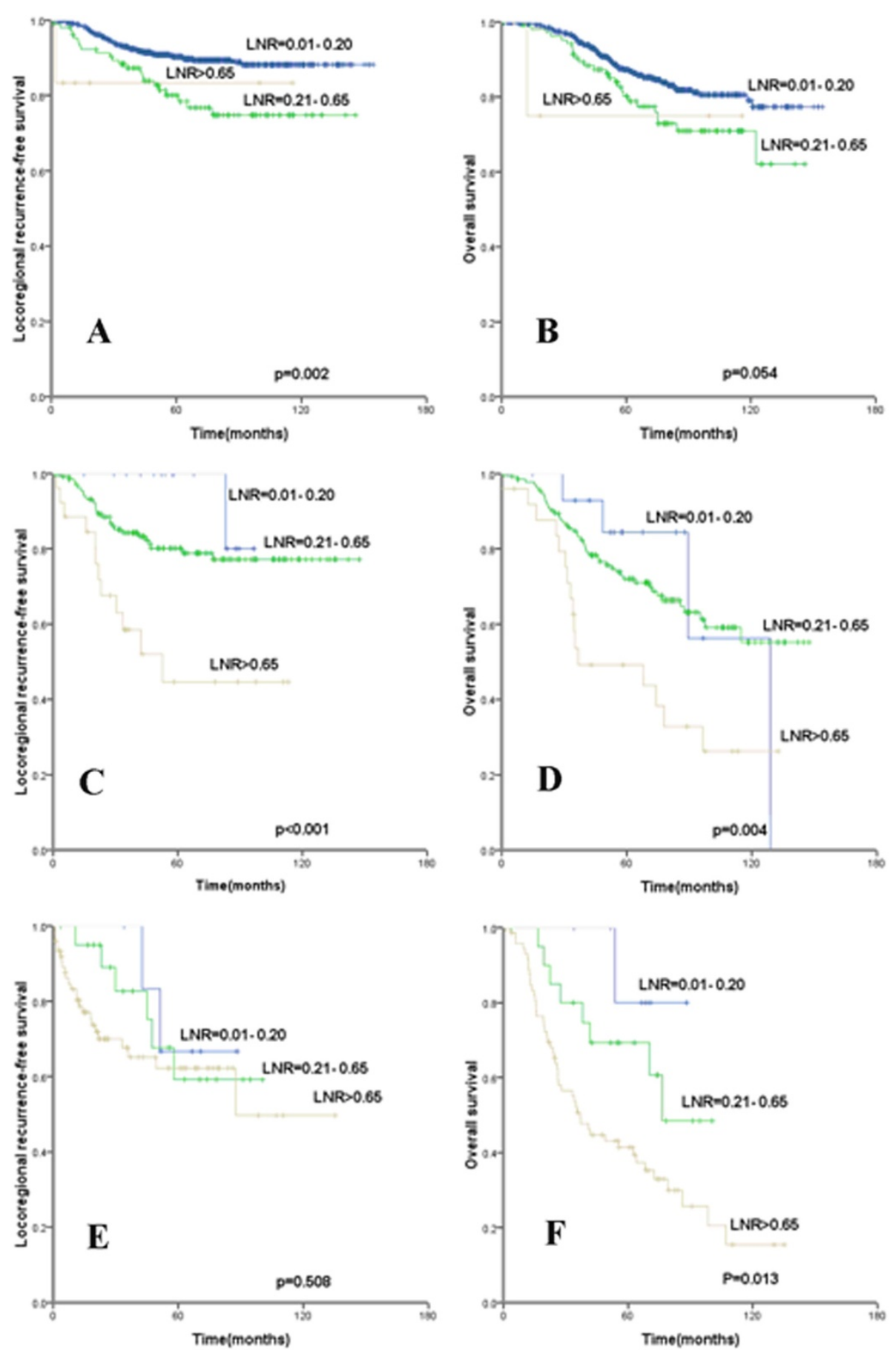

Figure 2 Kaplan-Meier cumulative survival curves for different lymph node ratio according to different pN stage. (A, C, E) Locoregional recurrence-free survival (LRFS) and (B, D, F) overall survival for $(\mathbf{A}, \mathbf{B}) \mathrm{pN1}$, and $(\mathbf{C}, \mathbf{D}) \mathrm{pN2}$, and $(\mathbf{E}, \mathbf{F}) \mathrm{pN} 3$.

a median number of lymph nodes removed of 18.6. In a study by Gentilini et al. [12] in which patients received no radiotherapy after mastectomy plus total axillary clearance (I/II/III region) where the median number of lymph nodes removed was 23, with the 5-year LRFS rates were 3.0\%, $8.1 \%$, and $9.9 \%$ for $\mathrm{N} 0, \mathrm{~N} 1$ and $\geq \mathrm{N} 2$ stage disease, respectively. These studies suggest that sufficient clearance of lymph nodes is helpful to reduce locoregional recurrence, and thereby affects the decision to administer adjuvant radiotherapy.

Physician differences and experience can affect the accuracy of $\mathrm{pN}$ staging. Due to variations in the clearance 
of axillary lymph nodes and different physical examination findings, the accuracy of $\mathrm{pN}$ staging can be compromised. Furthermore, the optimal number of the axillary lymph nodes that need to be removed remains controversial $[13,14]$. However, Fisher et al. [7] demonstrated that use of the LNR may minimize the difference in prognosis seen among hospitals due to different degrees of lymph node clearance. Several studies have shown that use of the LNR may change $\mathrm{pN}$ staging based on the AJCC system, and should be considered in addition to TNM staging in order to provide better guidance regarding adjuvant therapy [7,9,15-19]. Our study suggests that the LNR is an independent prognostic factor of LRFS and OS, and $\mathrm{pN}$ staging lost significance when LNR was included in the multivariate analysis. This suggests that LNR has better prognostic value than $\mathrm{pN}$ staging.

Locoregional recurrence is a determinant in the selection of adjuvant radiotherapy after mastectomy. The St. Gallen Breast Cancer Conference in 1998 recommended postoperative radiotherapy when the expected LRFS rate was $>20 \%$ [20]. In recent years, research has been concentrated on the effect of LNR on OS in patients with breast cancer [15-17], and the studies on LRFS have been mainly conducted in patients with 1-3 metastatic lymph nodes (pN1) [7,8]. Our study suggests that LNR is superior to $\mathrm{pN}$ staging as a predictor of LRFS in patients with breast cancer. We performed subgroup analysis of the prognostic value of LNR according to different $\mathrm{pN}$ stages, and for $\mathrm{pN} 1$ patients the 5-year and 10-year locoregional recurrence rates (LRR) were $20 \%$ and $25.2 \%$, and the LRR was above $20 \%$ in stage $\mathrm{pN} 2$ and $\mathrm{pN} 3$ patients across all LNR groups. The value of adjuvant radiotherapy in 1-3 metastatic lymph nodes is still controversial. Therefore, we recommend that LNR should be employed as one of the indications for adjuvant radiotherapy after mastectomy (i.e., radiation therapy should be considered if the LNR is > 0.20), instead of a treatment decision based only on pN stage.

Our study does have several limitations. First, the conclusions are based on a single center retrospective study and may not be generalizable to other populations. However, an increasing amount of data now supports the prognostic value of LNR in breast cancer, e.g., the International Nodal Ratio Working Group is currently undertaking research to establish the prognostic significance of LNR in breast cancer [19]. Second, there is no consensus on standard cutoff points for LNR $[7,9,18,19]$. The LNR cutoff points used in this study were based on the report by VinhHung et al., which has been validated in studies in other countries [15-17]. Our study suggests that the cutoff points for the LNR used by Vinh-Hung et al. are applicable to Chinese women with breast cancer, but a larger sample size is needed to confirm the results. Third, the prognostic value of Ki-67 was not analyzed due to missing data, and most of the patients did not received trastuzumab therapy.

\section{Conclusions}

In summary, our study demonstrated that LNR is a better prognostic predictor than $\mathrm{pN}$ stage in patients with axillary lymph node-positive breast cancer after mastectomy, and should be used as one of the indications for adjuvant radiation therapy. Further prospective studies are necessary to assess the impact of LNR on prognosis, and to define the usefulness of postoperative radiotherapy.

\section{Abbreviations \\ LNR: Lymph node ratio; ER: Estrogen receptor; PR: Progesterone receptor; Her-2: Human epithelial growth factor receptor family 2; LRFS: Locoregional recurrence-free survival; OS: Overall survival; CMF: Cyclophosphamide, methotrexate, and 5-fluorouracil; AJCC: American Joint Committee on Cancer; TNM: Tumor, regional lymph node, metastasis.}

\section{Competing interests}

The authors declare they have no competing interests of the article.

\section{Authors' contributions}

SGW,YC, and JYS carried out the data collection and writing of the manuscript; SGW helped to conceive the study; ZYH contributed to the design of the study; FYL and QL helped to collect data, HXL participated in statistical analysis. All authors read and approved the final manuscript.

\section{Acknowledgments}

This study was supported by a grant from Sci-Tech Office of Guangdong Province (No.2008B060 600019) and the Youth Foundation of the First Affiliated Hospital of Xiamen University (No. XYY2012005).

\section{Author details}

'Xiamen Cancer Center, Department of Radiation Oncology, the First Affiliated Hospital of Xiamen University, Xiamen 361003, People's Republic of China. ${ }^{2}$ State Key Laboratory of Oncology in Southern China, Sun Yat-Sen University Cancer Center, Guangzhou 510060, People's Republic of China. ${ }^{3}$ Department of Radiation Oncology, Sun Yat-Sen University Cancer Center, Guangzhou 510060, People's Republic of China.

Received: 19 November 2012 Accepted: 8 May 2013

Published: 14 May 2013

\section{References}

1. Overgaard M, Hansen PS, Overgaard J, et al: Postoperative radiotherapy in high-risk premenopausal women with breast cancer who receive adjuvant chemotherapy. Danish Breast Cancer Cooperative Group 82b Trial. N Engl J Med 1997, 337:949-955.

2. Overgaard $M$, Jensen $M B$, Overgaard J, et al: Postoperative radiotherapy in high-risk postmenopausal breast-cancer patients given adjuvant tamoxifen: Danish Breast Cancer Cooperative Group DBCG 82c randomised trial. Lancet 1999, 353:1641-1648.

3. Ragaz J, Olivotto IA, Spinelli JJ, et al: Locoregional radiation therapy in patients with high-risk breast cancer receiving adjuvant chemotherapy: 20-year results of the British Columbia randomized trial. J Natl Canc Inst 2005, 97:116-126.

4. Beenken SW, Urist MM, Zhang Y, et al: Axillary lymph node status, but not tumor size, predicts locoregional recurrence and overall survival after mastectomy for breast cancer. Ann Surg 2003, 237:732-738.

5. Singletary SE, Allred C, Ashley P, et al: Revision of the American Joint Committee on Cancer staging system for breast cancer. J Clin Oncol 2002, 20:3628-3636 
6. Veronesi U, Zurrida S, Viale G, Rethinking TNM, et al: A breast cancer classification to guide to treatment and facilitate research. Breast J 2009, 15:291-295

7. Truong PT, Woodward WA, Thames HD, et al: The ratio of positive to excised nodes identifies high-risk subsets and reduces inter-institutional differences in locoregional recurrence risk estimates in breast cancer patients with 1-3 positive nodes: an analysis of prospective data from British Columbia and the M. D. Anderson Cancer Center. Int I Radiat Oncol Biol Phys 2007, 68:59-65.

8. Han TJ, Kang EY, Jeon W, et al: The prognostic value of the nodal ratio in N1 breast cancer. Radiat Oncol 2011, 6:131.

9. Vinh-Hung V, Verkooijen HM, Fioretta $G$, et al: Lymph node ratio as an alternative to $\mathrm{pN}$ staging in node-positive breast cancer. $J$ Clin Oncol 2009, 27:1062-1068.

10. Overgaard M, Nielsen HM, Overgaard J: Is the benefit of postmastectomy irradiation limited to patients with four or more positive nodes, as recommended in international consensus reports? A subgroup analysis of the DBCG 82 b\&c randomized trials. Radiother Oncol 2007, 82:247-253.

11. Nagao T, Kinoshita T, Tamura N, et al: Locoregional recurrence risk factors in breast cancer patients with positive axillary lymph nodes and the impact of postmastectomy radiotherapy. Int J Clin Oncol 2013, 18:54-61.

12. Gentilini O, Botteri E, Rotmensz N, et al: Is avoiding post-mastectomy radiotherapy justified for patients with four or more involved axillary nodes and endocrine-responsive tumours? Lessons from a series in a single institution. Ann Oncol 2007, 18:1342-1347.

13. Steering Committee on Clinical Practice Guidelines for the Care and Treatment of Breast Cancer: Clinical practice guidelines for the care and treatment of breast cancer. CMAJ 1998, 158(Suppl 3):S1-S83.

14. Fisher B, Wolmark N, Bauer $M$, et al: The accuracy of clinical nodal staging and of limited axillary dissection as a determinant of histologic nodal status in carcinoma of the breast. Surg Gynecol Obstet 1981, 152:765-772.

15. Danko ME, Bennett KM, Zhai J, et al: Improved staging in node-positive breast cancer patients using lymph node ratio: results in 1,788 patients with long-term follow-up. J Am Coll Surg 2010, 210:797-805.

16. Chagpar AB, Camp RL, Rimm DL: Lymph node ratio should be considered for incorporation into staging for breast cancer. Ann Surg Oncol 2011, $18: 3143-3148$

17. Ahn SH, Kim HJ, Lee JW, et al: Lymph node ratio and pN staging in patients with node-positive breast cancer: a report from the Korean breast cancer society. Breast Canc Res Treat 2011, 130:507-515.

18. Castrucci W, Lannin $D$, Haffty $B G$, et al: Using nodal ratios to predict risk of regional recurrences in patients treated with breast conservation therapy with 4 or more positive lymph nodes. ISRN Surg 2011, 2011:874814.

19. Vinh-Hung V, Nguyen NP, Cserni G, et al: Prognostic value of nodal ratios in node-positive breast cancer: a compiled update. Future Oncol 2009, 5:1585-1603.

20. Goldhirsch A, Glick JH, Gelber RD, et al: Meeting highlights: International Consensus Panel on the Treatment of Primary Breast Cancer. J Natl Canc Inst 1998, 90:1601-1608.

doi:10.1186/1748-717X-8-119

Cite this article as: Wu et al:: Using the lymph nodal ratio to predict the risk of locoregional recurrence in lymph node-positive breast cancer patients treated with mastectomy without radiation therapy. Radiation Oncology 2013 8:119.

\section{Submit your next manuscript to BioMed Central and take full advantage of:}

- Convenient online submission

- Thorough peer review

- No space constraints or color figure charges

- Immediate publication on acceptance

- Inclusion in PubMed, CAS, Scopus and Google Scholar

- Research which is freely available for redistribution 